\title{
Memoria secuencial auditiva y memoria verbal en alumnado con discapacidad intelectual
}

\section{Juan A. Ramos Gutiérrez ${ }^{1,3}$, Carlos Valiente Barroso ${ }^{2,4}$}

\author{
${ }^{1}$ Universidad Complutense de Madrid \\ ${ }^{2}$ Centro Universitario Villanueva-Universidad Complutense de Madrid \\ ${ }^{3}$ Fundación Promiva - Colegio Virgen de Lourdes \\ ${ }^{4}$ Instituto Clínico y de Investigación Interdisciplinar en Neurociencias
}

\section{España}

Correspondencia: Juan Antonio Ramos Gutiérrez. Universidad Complutense de Madrid.

E-mail: jaramos@cop.es

(C) Universidad de Almería and Ilustre Colegio Oficial de la Psicología de Andalucía Oriental (Spain) 


\section{Resumen}

Introducción. El modelo de Baddeley sobre memoria de trabajo establece la base para identificar los componentes que intervienen en las tareas de repetición inmediata de materiales verbales. Partiendo del mismo, se propone este estudio cuyo objetivo general es analizar la relación entre memoria secuencial auditiva y memoria verbal en alumnado con discapacidad intelectual y, así, proponer una escala que permita comparar, según la edad mental, las puntuaciones de cada sujeto en estas pruebas.

Método. Estudio cuantitativo, no experimental, transversal, descriptivo y correlacional. Muestra no probabilística incidental en la que participaron 250 alumnos con discapacidad intelectual (123 alumnas y 127 alumnos), evaluados mediante el subtest de memoria secuencial auditiva del Test Illinois de Aptitudes Psicolingüísticas (ITPA) y las dos listas de oraciones con alta carga de significado y gramatical del Test Sentence Repetition (SentRep).

Resultados. Se observan relaciones significativas y positivas entre las listas de mediación semántica y morfosintáctica, y la memoria verbal, e igualmente entre cada una de ellas, la edad mental del sujeto y la memoria secuencial auditiva. Resultados que sustentan la construcción de dos baremos para establecer la edad mental equivalente a la repetición de los dos tipos de oraciones, en memoria verbal y en memoria secuencial auditiva.

Discusión/Conclusiones. Se ha demostrado la complementariedad de las pruebas aplicadas y que los baremos construidos permiten comparar las puntuaciones obtenidas por un sujeto en relación a su grupo. No obstante, una propuesta futura es extender la muestra y, de este modo, obtener baremos representativos de la población con discapacidad intelectual que apoyen la formulación de hipótesis diagnósticas sobre el nivel funcional alcanzado por este alumnado en el procesamiento fonológico, sintáctico y semántico.

Palabras Clave: Memoria de trabajo, repetición de oraciones, evaluación neuropsicológica, lenguaje, discapacidad intelectual. 


\begin{abstract}
Introduction. Baddeley's model of working memory establishes the basis for identifying the components that intervene in the tasks of immediate repetition of verbal materials. Based on the same, this study is proposed whose general objective is to analyze the relationship between auditory sequential memory and verbal memory in students with intellectual disabilities and thus propose a scale that allows comparing, according to mental age, the scores of each subject in these tests.

Method. Quantitative, non-experimental, cross-sectional, descriptive and correlational study. Incidental non-probabilistic sample in which 250 students with intellectual disabilities (123 students and 127 students) participated, evaluated by means of the auditory sequential memory subtest of the Illinois Test of Psycholinguistic Aptitudes (ITPA) and the two lists of sentences with high load of meaning and grammar of the Test Sentence Repetition (SentRep).

Results. Significant and positive relationships are observed between the lists of semantic and morph syntactic mediation and verbal memory, and also between each one, the subject's mental age and sequential auditory memory. Results that support the construction of two scales to establish the mental age equivalent to the repetition of the two types of sentences, in verbal memory and in auditory sequential memory.

Discussion/Conclusion. The complementarity of the applied tests has been demonstrated and that the constructed scales allow comparing the scores obtained by a subject in relation to their group. However, a future proposal is to extend the sample and thus obtain representative scales of the population with intellectual disabilities that support the formulation of diagnostic hypotheses about the functional level reached by this student in phonological, syntactic and semantic processing
\end{abstract}

Keywords: Working memory, sentence repetition, neuropsychological assessment, language, intellectual disability. 


\section{Introducción}

A lo largo de diferentes épocas y de sus planteamientos teóricos se ha tratado la discapacidad intelectual en la infancia y adolescencia y su intervención educativa, pasando de un modelo meramente de carácter asistencial a un modelo centrado en la educabilidad de las personas que evoluciona a partir de la segunda mitad del siglo pasado, y que se centra en la posibilidad de potenciar las funciones y los recursos cognitivos de este alumnado. Todas las conceptualizaciones de la discapacidad intelectual tienen en común la presencia de limitaciones significativas a nivel cognitivo, pero también en la conducta adaptativa al entorno que rodea a estas personas. Según el DSM-5 (APA, 2013), se define el trastorno del desarrollo intelectual como un "déficit de las capacidades mentales generales, como el razonamiento, la resolución de problemas, la planificación, el pensamiento abstracto, el juicio, el aprendizaje académico y el aprendizaje de la experiencia" (p. 31). Dentro de estos déficits que provocan en el alumnado dificultades de adaptación y de adquisición de la autonomía e independencia, se encuentran algunos relacionados con la comunicación, que es previa al lenguaje y que por lo tanto pueden interferir en su aprendizaje (Guerra y De la Peña, 2017).

El alumnado con discapacidad intelectual suele tener alteraciones en la comunicación verbal que, según las características individuales y el grado de discapacidad, influyen en la intensidad y tipología de las alteraciones lingüísticas que dificultan la organización y expresión de la información, y que se dan tanto a nivel fonológico, semántico y morfosintáctico como pragmático (Peña-Casanova, 2013). Se han llevado a cabo estudios que evidencian que el aprendizaje del alumnado con discapacidad intelectual se facilita mediante el uso de estrategias que combinan el lenguaje no verbal y verbal, y cómo la atención y la memoria influyen en la comprensión e interpretación de la información que una vez relacionada con los conocimientos previos favorece la significatividad del aprendizaje (Miolo, Chapman y Sindberg, 2005; Stephenson y Dowrick, 2005). Con base en estas dificultades, las tareas de repetición de dígitos, sílabas, pseudopalabras, palabras y oraciones se han utilizado en la evaluación del alumnado con discapacidad intelectual. Sin embargo, son escasos los estudios que han intentado integrarlas en una teoría y, a partir de ella, crear instrumentos y procedimientos de interpretación, evaluación y diagnóstico de los componentes y procesos que intervienen en dichas tareas (Sedó, 2004). 
Para resolver los problemas de interpretación, el modelo más utilizado ha sido el de la memoria de trabajo de Baddeley, que explica cuáles son los constituyentes implicados en las tareas de repetición inmediata de materiales verbales, cómo actúan y se relacionan entre sí. Tanto en su versión original (Baddeley, 1986; Baddeley y Hitch, 1974) como en sus revisiones posteriores (Badeley, 2000, 2007, 2010, 2012; Baddeley y Hitch, 1994; Baddeley, Hitch y Allen, 2009), este modelo ha recibido gran apoyo desde la Psicología cognitiva y la Neurociencia.

La investigación generada al respecto ha demostrado que la memoria de trabajo se relaciona estrechamente con el nivel de ejecución que las personas alcanzan en numerosas tareas cognitivas, y con la forma en la que afrontan las tareas de la vida diaria (D'Esposito y Postle, 2015; García-Madruga y Fernández, 2008; Pelegrina, Lechuga, Castellanos y Elosúa, 2016). También se ha demostrado que esta memoria es esencial en la comprensión de la información y posterior transferencia del aprendizaje a otros contextos, y parece ser mejor predictora del rendimiento académico que el CI, lo que apoyaría su fuerte relación con el aprendizaje (Alloway y Alloway, 2010; Soprano y Narbona, 2007).

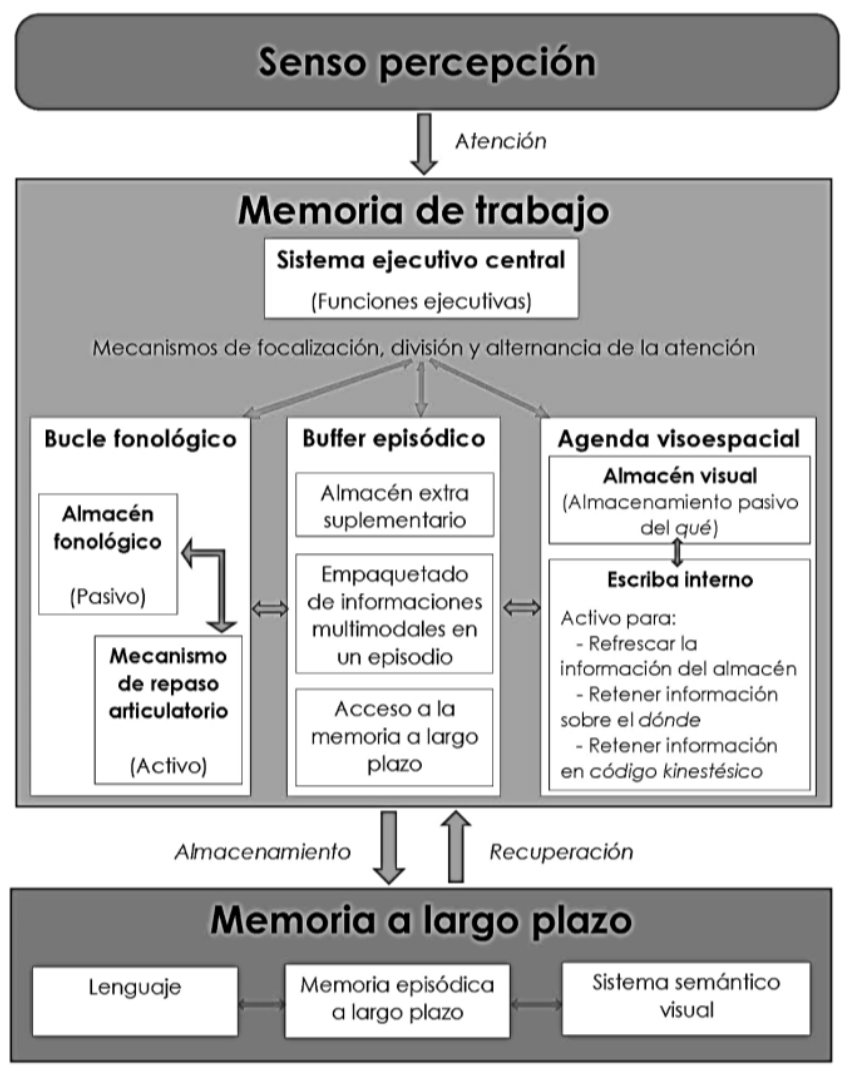

Figura 1. Modelo multicomponente de memoria de trabajo adaptado de Baddeley (2000, 2007, 2012). (Fuente: elaboración propia) 
El modelo sobre la memoria de trabajo de Baddeley es un modelo integrador que propone un sistema de cuatro componentes: sistema ejecutivo central, bucle fonológico, buffer episódico y agenda visoespacial (ver Figura 1), que explica cómo registramos, mantenemos y manipulamos transitoriamente la información al realizar tareas complejas tales como la comprensión del lenguaje, la lectura, el razonamiento, la resolución de problemas, etc. (Baddeley y Lieberman, 2017).

El sistema ejecutivo central es un componente activo que está relacionado con las funciones ejecutivas que implican preponderantemente a la corteza prefrontal (D'Esposito y Postle, 2015; De Noreña, Blázquez, González y Gil, 2012; Goldman-Rakic, 1998; RuizVargas, 2010; Tirapu-Ustárroz y Grandi, 2016). Dentro del modelo, el ejecutivo central supervisa y ejerce un control general sobre los otros componentes, distribuyendo y asignando los recursos de procesamiento mediante el empleo de los mecanismos de focalización, división y alternancia de la atención. Pero este sistema carece de capacidad de almacenamiento, por lo que realiza sus funciones con la información almacenada provisionalmente en los otros sistemas.

El bucle fonológico está especializado en el almacenamiento temporal de pequeñas cantidades de información verbal escuchada, que permanecen disponibles durante períodos de tiempo muy cortos. Es un proceso muy importante para la adquisición del lenguaje en la primera infancia (Hamada y Koda, 2011; Verhagen y Leseman, 2016; Weill, 2011) y de la lectoescritura en la edad escolar (Swanson, Zheng y Jerman, 2009). Neuroanatómicamente está íntimamente vinculado con estructuras y vías dorsales del hemisferio izquierdo relacionadas con el procesamiento de los sonidos del habla y su integración sensorio-motora, en especial con el área de Wernicke, el giro angular, el giro supramarginal, el córtex premotor, la ínsula anterior, el córtex frontal inferior posterior y las secciones anterior y posterior del fascículo arqueado que conectan todas estas áreas (Adrover, Marron, Sánchez y Miranda, 2014; Friederici y Gierhan, 2013; Hickok y Poeppel, 2015; Tirapu-Ustárroz y Grandi, 2016). El bucle fonológico se divide en dos componentes, el primero es el almacén fonológico al que accede la información oída de manera obligatoria y automática, manteniéndose por períodos cortos de tiempo de una forma pasiva, pues la huella de memoria decae rápidamente. Es similar a la memoria secuencial auditiva a corto plazo, representativa de la capacidad primaria de la me- 
moria secuencial fonológica a corto plazo (Baddeley, 2012; Cowan, 2008). El segundo componente es el mecanismo de repaso articulatorio (explícito o encubierto), que es un proceso más activo en el que se refresca la información almacenada, previniendo su rápido desvanecimiento mediante un bucle repetitivo, y en el que además se transforma mediante pronunciación la información visual (palabras escritas, letras, números, imágenes, etc.) en etiquetas verbales (recodificación de lo visual en fonológico) (Manso y Ballesteros, 2003).

El buffer episódico es un componente que se introduce en las revisiones más actuales del modelo (Baddeley, 2000, 2007, 2012; Baddeley et al., 2009). Se trata de un sistema de almacenamiento temporal y de capacidad limitada, cuyas bases orgánicas son bastante complejas, pues tomando como elementos integradores al hipocampo y la corteza prefrontal ventromedial, comprenden dos redes. La primera de ellas especifica para el individuo el valor conceptual y motivacional de las entidades presentes, mediante la acción conjunta del córtex perirrinal, la amígdala, el córtex temporoventral anterior y el córtex orbitofrontal lateral. La segunda de ellas, crea un modelo mental de la situación que contiene marcadores espaciotemporales, mentalistas y sociales, mediante la acción conjunta del córtex parahipocampal, el córtex retroesplenial, el cingulado posterior, el precuneus, el giro angular, los cuerpos mamilares, el tálamo anterior y el córtex prefrontal medial (Ranganath y Ritchey, 2012; Ritchey, Libby y Ranganath, 2015). A diferencia de la agenda visoespacial y del bucle fonológico, el buffer episódico es multimodal y multidimensional, pues se encarga de integrar la información de la agenda y el bucle (que almacenan y codifican inputs senso-perceptivos específicos de la experiencia en curso), con el conocimiento almacenado en la memoria a largo plazo (conocimientos semántico-visuales, lingüísticos, de la memoria episódica, etc.). Con todo ello genera una representación unitaria coherente (un episodio) que permite obtener una sensación subjetiva consciente de experiencia vivenciada. Entre sus principales funciones está servir de almacén extra, suplementando al bucle fonológico y la agenda visoespacial; permitir el acceso al conocimiento almacenado en la memoria a largo plazo relacionado con la tarea en curso y el input sensorial perceptivo, facilitando el uso de ese conocimiento previo por todos los componentes del sistema y, además, empaquetar las distintas informaciones multimodales conformando un episodio consciente, coherente y significativo.

Por último, la agenda visoespacial está especializada en mantener almacenada transitoriamente (durante breves períodos de tiempo) tres tipos de información: visual con significado, visoespacial y kinestésica (Baddeley, 2012; Galvez-Pol, Forster y Calvo-Merino, 2018; 
Smith y Pendleton, 1990). Neuroanatómicamente se relaciona con áreas parietales, occipitotemporales, el campo visual frontal y el giro frontal inferior (Adrover et al., 2014). Dentro de la agenda se diferencia un componente pasivo (caché o almacén visual) que es el responsable del almacenamiento pasivo de la información visual y un componente activo (escriba interno) que se ocupa de repasar y refrescar la información visual del caché, retener información sobre localizaciones y retener información sobre secuencias de movimientos (Logie, 2011).

El modelo de Baddeley defiende que existen algunos factores que pueden incrementar la amplitud primaria de la memoria, como pueden ser el repaso, o el uso de estrategias de recodificación u organización de la información (chunking). En cuanto a la recodificación, la capacidad limitada de la memoria primaria puede ser superada mediante el agrupamiento de varios ítems en unidades de orden superior o chunks (varios elementos combinados en una sola unidad constituyen un chunk). Por ejemplo, si hay que recordar la secuencia "p, s, l, k" se trata de 4 unidades, pero si hay que recordar "p, e, s, o", y agrupamos esas letras en la palabra "peso", se trataría sólo de una unidad. Lo mismo se puede decir cuando hay que recordar listas de palabras si es posible agruparlas en una oración. Esto es posible gracias a los procesos que se llevan a cabo en el búfer episódico que, como se ha señalado, está interconectado con los restantes componentes de la memoria de trabajo (que se hacen cargo de las entradas sensoperceptivas y del control de la actividad) y la memoria a largo plazo (conocimientos previos), lo cual lo sitúa en una posición privilegiada para integrar y organizar la información.

Respecto a la memoria de trabajo para material verbal, Baddeley y Lieberman (2017) indican que existe un efecto de superioridad del recuerdo inmediato de oraciones frente al de listas de palabras no relacionadas (efecto de superioridad de las oraciones). Según estos autores los procesos ejecutivos y atencionales no son cruciales para que se produzca este efecto, pues está vinculado a la codificación automática semántica y morfosintáctica de las oraciones en el búfer episódico, con apoyo en conocimientos y capacidades previas. Es decir, la memoria para oraciones (tanto con fuerte carga semántica -oraciones naturales abiertas-, como con fuerte carga morfosintáctica -oraciones restrictivas-) se beneficia de un proceso en el que el almacenamiento a corto plazo de la entrada fonológica (en el almacén fonológico) interactúa con el conocimiento previo semántico y lingüístico para unir grupos de elementos en fragmentos mayores. El buffer episódico sería el responsable de la integración de los diferentes tipos de información, apoyándose principalmente en la codificación automática basada en 
procesos secuenciales morfo-sintácticos (en el caso de las oraciones restrictivas), y en mecanismos automáticos de codificación semántica basados en el sentido (en el caso de las oraciones naturales abiertas).

En la producción verbal del alumnado con necesidades especiales, y, dentro de estos, los que presentan trastorno del desarrollo intelectual, se han observado alteraciones frecuentes a nivel fonológico, presentando déficits en la habilidad para repetir secuencias de estímulos fonológicos no significativos o memoria secuencial auditiva, la cual precisa del almacenaje y posterior recuerdo de información verbal y auditiva siguiendo el mismo orden de presentación inicial (Kirk, McCarthy y Kirk, 2004). Estudios previos confirman que el déficit en el componente fonológico se asocia a bajas habilidades psicolingüísticas y, dentro de estas, a la memoria secuencial auditiva y verbal, que interfieren en el análisis y recuerdo de una palabra y, en consecuencia, en su posterior y correcta reproducción. Por lo que se precisan habilidades de autorregulación y atencionales desarrolladas a través de mecanismos especializados (Arévalo y León, 2019; Fernández y Gràcia, 2013; Hidalgo, 2014; Muñoz, González y Lucero, 2009).

En los centros educativos, se han utilizado conjuntamente pruebas relativas a la memoria secuencial auditiva y de la memoria verbal, que, si bien pueden ser complementarias, no han permitido integrarlas en un solo procedimiento apto para la evaluación y diagnóstico de la discapacidad intelectual. Muchas de las dificultades se encuentran en la interpretación de los datos obtenidos en algunos de los instrumentos existente, y la ausencia de un modelo general que permita establecer cuáles son las funciones mentales que intervienen en las tareas de cada prueba y cómo se relacionan entre sí.

\section{Objetivos}

Con la finalidad de optimizar la evaluación, el diagnóstico y la intervención en el alumnado con discapacidad intelectual, se propone este estudio cuyo objetivo general es analizar las relaciones entre memoria secuencial auditiva y memoria verbal teniendo en cuenta la edad mental del alumnado con este tipo de trastorno del neurodesarrollo. De esta manera, se pretenden establecer unos índices a partir de las puntuaciones obtenidas que permitan realizar interpretaciones sobre ambas memorias según la edad mental de cada sujeto, y así poder compararlo consigo mismo y en relación a su grupo, contrastando la evolución alcanzada en cada una de estas memorias pudiendo detectar puntos fuertes y débiles del desarrollo del sujeto. 


\section{Método}

\section{Participantes}

Muestra no probabilística incidental en la que inicialmente participaron 265 estudiantes con discapacidad intelectual que cursaban en un colegio de Educación Especial de la Comunidad Autónoma de Madrid, España. Los datos obtenidos formaban parte de los resultados de las evaluaciones psicopedagógicas que con fines educativos se realizan con el alumnado del colegio.

A estos alumnos y alumnas, además de una versión adaptada del SentRep (cada lista se pasó desde el primer ítem), se les aplicó también la prueba de memoria secuencial auditiva (MSA) del Test Illinois de Aptitudes Psicolingüísticas (ITPA), que sirvió como criterio para establecer la edad mental alcanzada por cada alumno y alumna en las funciones propias del almacén fonológico, puesto que no era posible trabajar con su edad cronológica al padecer discapacidad intelectual.

Tras aplicar la prueba criterio a los sujetos, se seleccionaron aquellos casos en los que, en función de las puntuaciones directas conseguidas en la prueba, se les podía atribuir una edad mental equivalente. Así, la muestra definitiva se vio reducida a 250 alumnos con discapacidad intelectual, 127 hombres y 123 mujeres, con edades cronológicas comprendidas entre los 7 y los 20 años, y con un CI medio de 48 evaluado a través del WISC-IV (Wechsler, 2005).

\section{Instrumentos}

Test Illinois de Aptitudes Psicolingüísticas (ITPA) (Kirk et al., 2004), adaptación española de Ballesteros y Cordero (2011). Consta de 12 subtests, aplicables en alumnado entre 3 y 10 años, que evalúan las habilidades psicolingüísticas del niño a nivel representativo y automático. El objetivo fundamental de este test consiste en detectar la existencia de alteraciones o dificultades en el proceso de comunicación (deficiencias en la percepción, interpretación o transmisión), que pueden estar en la base de la mayoría de los problemas del aprendizaje escolar. A su vez, de modo complementario, pretende explicitar las habilidades o condiciones positivas que puedan servir de apoyo a un programa de recuperación. En este estudio se emplea el subtest de memoria secuencial auditiva (MSA) que se encuentra entre las pruebas más utilizadas en la evaluación del alumnado con discapacidad intelectual. Consta de 26 series que 
evalúan el recuerdo inmediato de material verbal no significativo, a través de la repetición de series de dos a ocho dígitos presentados a una velocidad de dos por segundo. Se presenta una serie cada vez para que el sujeto la repita y diga lo que recuerda y la prueba se detiene cuando este fracasa en tres series consecutivas. Consistencia interna medida con el coeficiente alpha de Cronbach de cada escala del instrumento y según la edad con valores entre .74-.90 y en la prueba de memoria secuencial auditiva entre .79-.87.

Test Sentence Repetition (SentRep) de Sedó (1990, 2004). Test de repetición de oraciones que introduce una comparación entre dos series de oraciones de longitud idéntica que difieren tan sólo en el uso de una sintaxis simple o una sintaxis compleja. Las dos listas tienen una longitud creciente y alcanzan la treintena de sílabas.

Longitud: La lista L utiliza sólo palabras bisílabas, lo que permite controlar perfectamente la longitud de las oraciones, que aumenta añadiendo una palabra bisílaba después de cada dos oraciones de la misma longitud (2, 2, 4, 4, 6, 6, 8, 8 sílabas, etc.).

Complejidad: En la lista C, la longitud aumenta sólo una sílaba cada vez, pero la estructura de la oración es marcadamente diferente, pues introduce un gran número de marcadores morfo-sintácticos (género, número, tiempos verbales, verbos dobles, interrogaciones, formas compuestas, etc.). Ejemplos de oraciones L y C (en cursiva) de la misma longitud:

\section{2: Adiós}

2: Se fue

4: Buenas noches

4: No me lo dio

6: Hace mucho calor

6: ¿Qué más quieren hacer?

Aunque en la prueba original existen puntos de inicio según la edad, en este estudio se ha aplicado cada lista desde el primer ítem, dado que los participantes en el estudio presentan discapacidad intelectual. Esta prueba permite comparar a los sujetos no sólo con normas externas, sino también consigo mismos, en sus reacciones ante la lista L y la lista C. 
Constituye una prueba de uso clínico que puede complementar a la prueba de memoria secuencial auditiva del ITPA, pues introduce una comparación entre la repetición inmediata de dos listas de oraciones de longitud creciente respecto al número de sílabas, que difieren tan sólo en el uso de una sintaxis simple o una sintaxis compleja. Mediante el uso del SentRep se puede establecer: 1) un índice del desarrollo de la memoria verbal inmediata cuando esta está mediada fundamentalmente por la simple comprensión verbal (lista L): 2) un índice del desarrollo de la memoria verbal inmediata cuando esta se basa en la comprensión lingüística de la complejidad de la frase y en el nivel de la gramática expresiva del sujeto -dado que no se pueden repetir con exactitud más que las oraciones que ya se saben producir espontáneamente(lista C); y 3) una puntuación "ipsativa" (C - L) que permite, comparando al sujeto consigo mismo, contrastar la evolución alcanzada en cada una de estas memorias respecto a la otra, detectando puntos fuertes y débiles del desarrollo del sujeto.

\section{Procedimiento}

Se diseñó un estudio de metodología cuantitativa, no experimental, transversal, descriptivo y correlacional. Se recogieron los datos en las distintas evaluaciones que se integran dentro del protocolo de actuación psicoeducativa del centro, llevándose a cabo durante el horario lectivo. En todos los casos, los padres o tutores legales de los alumnos y alumnas firmaron previamente un consentimiento informado, en el que además se les garantizaba la estricta confidencialidad, carácter anónimo y cuidadosa custodia de los datos recogidos por parte del equipo investigador. El estudio no hubo de ser revisado por ninguna comisión, dado que los diseños de investigación prospectivos no precisan ser aprobados por un comité ético.

\section{Análisis de datos}

Se realizó un análisis factorial exploratorio con el método de componentes principales con rotación varimax, para validar la escala conformada con las puntuaciones obtenidas en cada una de las pruebas aplicadas. Para comprobar si los datos eran factorizables se examinaron las medidas de adecuación de Kaiser-Meyer-Olkin (KMO), que sugiere la presencia de un factor latente cuando su valor está próximo a 1. Se confirmó mediante la prueba de esfericidad de Bartlett que constata que cuando el nivel de significación de este estadístico es mayor que .05 no tiene sentido realizar un análisis factorial del instrumento. Además, se estudió la fiabilidad a través del análisis de consistencia interna calculando el coeficiente alpha de Cronbach, que se basa en la correlación inter-elementos promedio asumiendo que los ítems de 
los cuestionarios están fuertemente correlacionados. Los valores de este coeficiente oscilan entre 0 y 1 , y se considera aceptable cuando su valor es igual o superior a 0.70 .

En segundo lugar, se calcularon las correlaciones entre las puntuaciones de las escalas consideradas en el estudio y la edad mental equivalente con el coeficiente de correlación de Pearson. En base a las relaciones encontradas, se confeccionaron dos baremos para establecer la equivalencia en cada uno de los componentes que intervienen en la repetición de oraciones, las edades mentales equivalentes a las puntuaciones directas conseguidas, así como las puntuaciones ipsativas correspondientes a cada edad mental. Al no ser posible utilizar la edad cronológica del alumnado con discapacidad intelectual como criterio de normalización con esta población, se utilizó la edad mental equivalente alcanzada en la prueba de memoria secuencial auditiva del ITPA (Kirk et al., 2004), dada su relación con la amplitud primaria del almacén fonológico, que es la primera de las capacidades en desarrollarse (Catani y Bambini, 2014). De esta manera, se crearon nuevas puntuaciones que permiten complementar las posibilidades de evaluación del SentRep, combinándolas con la significación y potencialidades de la prueba de memoria secuencial auditiva del ITPA, y así comparar las puntuaciones de dichas escalas según la edad mental del sujeto.

El diseño de la base de datos, así como todos los análisis estadísticos se realizaron mediante el paquete estadístico SPSS versión 24.0 para Windows.

\section{Resultados}

Previo al análisis factorial exploratorio se revisan las medidas de adecuación muestral con el coeficiente KMO que fue .737 y la prueba de esfericidad de Bartlett $\left(\chi^{2}=3648.771, p\right.$ $<.001)$, resultados que indican la pertinencia de proceder al análisis factorial exploratorio. El análisis factorial exploratorio de componentes principales con rotación varimax de la escala considerada en este estudio, muestra una solución inicial de un único factor que explica el $86.11 \%$ de la varianza total del constructo. Respecto a las cargas factoriales, todas oscilan entre .902 y .964, valores considerados fuertes (Kline, 2014). En la Tabla 1 se muestran los estadísticos descriptivos y las cargas factoriales de las cinco medidas consideradas en este estudio. Además, la consistencia interna global de la escala construida evaluada a través del estadístico alpha de Cronbach es de .889 , indicativo de una fiabilidad alta. 
Tabla 1. Estadísticos descriptivos y cargas factoriales de las pruebas del estudio.

\begin{tabular}{lcccccc}
\hline & $\boldsymbol{M}$ & $\boldsymbol{D T}$ & Mín-Máx & Asimetría & Curtosis & Carga factorial \\
\hline EM & 6.07 & 1.89 & $3-10$ & .35 & -.82 & .920 \\
MSA & 7.88 & 3.42 & $1-16$ & .32 & -.59 & .920 \\
Lista L & 15.24 & 4.74 & $0-28$ & .02 & .79 & .902 \\
Lista C & 12.32 & 6.00 & $0-23$ & .15 & -1.21 & .932 \\
MV & 27.56 & 10.21 & $0-51$ & .08 & -.57 & .964 \\
\hline
\end{tabular}

EM: edad mental; MSA: memoria secuencial auditiva; Lista L: mediación semántica con alta carga de significado; Lista C: mediación morfosintáctica con alta carga gramatical; MV: memoria verbal (L+C)

Por otro lado, se realiza el análisis correlacional cuyos resultados se presentan en la Tabla 2. Se observan relaciones significativas y positivas entre las listas de mediación semántica, de mediación morfosintáctica y memoria verbal, así como entre todas ellas y la edad mental del sujeto y la memoria secuencial auditiva. Estos resultados sustentan la posibilidad de que estas puntuaciones puedan ser utilizadas para establecer un baremo en el que se asocien las edades equivalentes a las puntuaciones directas conseguidas en cada una de las listas y en memoria verbal, y así poder comparar a cada sujeto consigo mismo y dentro del grupo al que pertenece.

Tabla 2. Correlaciones entre edad mental, memoria secuencial auditiva, mediación semántica, mediación morfosintáctica y memoria verbal

\begin{tabular}{lccccc}
\hline & EM & MSA & Lista L & Lista C & MV \\
\hline EM & 1 & & & & \\
MSA & $.998^{* *}$ & 1 & & & \\
Lista L & $.715^{* *}$ & $.719^{* *}$ & 1 & & \\
Lista C & $.773^{* *}$ & $.770^{* *}$ & $.813^{* *}$ & 1 & \\
MV & $.784^{* *}$ & $.785^{* *}$ & $.938^{* *}$ & $.963^{* *}$ & 1 \\
\hline
\end{tabular}

EM: edad mental; MSA: memoria secuencial auditiva; Lista L: mediación semántica con alta carga de significado; Lista C: mediación morfosintáctica con alta carga gramatical; MV: memoria verbal $(\mathrm{L}+\mathrm{C})$ ${ }^{* *} p<.01$

A partir de las edades mentales equivalentes asignadas a cada uno de los participantes en memoria secuencial auditiva, se configuran grupos asociando a cada uno de ellos las puntuaciones directas equivalentes a esta puntuación, la de cada lista de oraciones (L-semántica y C-morfosintáctica) y la de memoria verbal. Los resultados aparecen en la Tabla 3 y permiten, partiendo de las puntuaciones directas que un alumno o alumna obtenga en las dos listas de 
oraciones ( $\mathrm{L}$ y C) y en memoria verbal, calcular qué edad equivalente le corresponde en memoria verbal a corto plazo mediada semánticamente, en memoria verbal a corto plazo mediada morfosintácticamente, y en memoria verbal total. Estas equivalencias facilitan extraer conclusiones sobre el desarrollo de la memoria inmediata ligada a las capacidades verbalessemánticas automáticas, a las aptitudes morfosintácticas automáticas, y a las capacidades verbales automáticas en general.

Tabla 3. Medias y desviaciones típicas de los grupos edad mental

\begin{tabular}{lccccc}
\hline $\begin{array}{l}\text { Edad Mental } \\
\text { (años-meses) }\end{array}$ & N & MSA & $\begin{array}{c}\text { Lista L } \\
\text { Sílabas } M(D T)\end{array}$ & $\begin{array}{c}\text { Lista C } \\
\text { Sílabas } M(D T)\end{array}$ & $\begin{array}{c}\text { MV } \\
\text { Sílabas } M(D T)\end{array}$ \\
\hline $3-6$ & 31 & 3 & $8,7(3,8)$ & $4,9(2,6)$ & $13,8(5,7)$ \\
$4-2$ & 31 & 4,5 & $11,6(2)$ & $6,8(1,7)$ & $18,5(2,9)$ \\
$4-9$ & 31 & 5,7 & $14,2(2,4)$ & $9,5(3,4)$ & $23,7(4,8)$ \\
$5-7$ & 32 & 7,1 & $14,3(3,4)$ & $10,3(5)$ & $24,7(7,8)$ \\
$6-4$ & 32 & 8,3 & $16,3(2,9)$ & $13,2(4,1)$ & $29,5(6,1)$ \\
$7-0$ & 31 & 9,5 & $17,2(2,8)$ & $16,2(3,7)$ & $33,3(5,8)$ \\
$7-10$ & 31 & 11 & $19,1(3,7)$ & $18,1(3,1)$ & $37,2(6,1)$ \\
$9-6$ & 31 & 14 & $20,5(3,5)$ & $19,5(2,7)$ & $40(5,6)$ \\
& & & & & \\
\hline
\end{tabular}

MSA: memoria secuencial auditiva; Lista L: mediación semántica con alta carga de significado; Lista C: mediación morfosintáctica con alta carga gramatical; MV: memoria verbal $(\mathrm{L}+\mathrm{C})$

Asimismo, como se observa en la Tabla 4, partiendo de las puntuaciones directas se calculan puntuaciones ipsativas que, referenciadas a la edad mental equivalente alcanzada por el alumnado en memoria verbal y memoria secuencial auditiva, indicarán respectivamente si existen diferencias estadísticamente significativas o no entre el recuerdo de ambas listas de oraciones o entre memoria verbal y memoria secuencial auditiva (siempre y cuando la diferencia sea superior a una desviación típica). Esto permitirá analizar la homogeneidad o heterogeneidad del desarrollo de estos componentes del recuerdo inmediato de materiales verbales. Así, para comparar la memoria verbal y la memoria secuencial auditiva se toma el grupo de edad más próximo a la edad conseguida en memoria secuencial auditiva y, para la comparación C-L se toma el grupo de edad más próximo a la edad conseguida en memoria verbal. En ambos casos, si la edad está en el punto medio entre dos grupos, se deberá elegir el de mayor edad, y en los extremos se deberá usar el primer o el último grupo. 


\begin{tabular}{lccccc}
\hline $\begin{array}{l}\text { Edad Mental } \\
\text { (años-meses) }\end{array}$ & N & $\begin{array}{c}\text { P. Ipsativa } \\
M(D T)\end{array}$ & $\begin{array}{c}\text { (Diferen: C-L) } \\
\text { Intervalo }\end{array}$ & $\begin{array}{c}\text { P. Ipsativa } \\
M(D T)\end{array}$ & $\begin{array}{c}\text { (Diferen. MV-MSA) } \\
\text { Intervalo }\end{array}$ \\
\hline $3-6$ & 31 & $-3,7(3,2)$ & $\cdot-0,5: \geq 0$ & $10,8(5,7)$ & $\cdot 16,5: \geq 17$ \\
& & & $\cdot-6,9: \leq-7$ & & $\cdot 5,1: \leq 5$ \\
$4-2$ & 31 & $-4,8(2,3)$ & $\cdot-2,5: \geq-2$ & $13,9(3,1)$ & $\cdot 17: \geq 18$ \\
& & $\cdot-7,1: \leq-8$ & & $\cdot 10,8: \leq 10$ \\
$4-9$ & 31 & $-4,7(3,9)$ & $\cdot-1,3: \geq-1$ & $18,0(4,9)$ & $\cdot 23,4: \geq 24$ \\
& & & $\cdot-8,3: \leq-9$ & & $\cdot 13,2: \leq 13$ \\
$5-7$ & 32 & $-4,0(3,3)$ & $\cdot-0,7: \geq 0$ & $17,6(8,1)$ & $\cdot 25,7: \geq 26$ \\
& & & $\cdot-7,3: \leq-8$ & & $\cdot 9,5: \leq 9$ \\
$6-4$ & 32 & $-3,1(3,7)$ & $\cdot 0,6: \geq 1$ & $21,2(6,4)$ & $\cdot 27,6: \geq 28$ \\
& & & $\cdot-6,8: \leq-7$ & & $\cdot 14,8: \leq 14$ \\
$7-0$ & 31 & $-1,0(3,2)$ & $\cdot 2,2: \geq 3$ & $23,8(6,1)$ & $\cdot 29,9: \geq 30$ \\
& & & $\cdot-4,2: \leq-5$ & & $\cdot 17,7: \leq 17$ \\
$7-10$ & 31 & $-1,0(3,1)$ & $\cdot 2,1: \geq 3$ & $26,2(6,0)$ & $\cdot 32,2: \geq 33$ \\
& & & $\cdot-4,1: \leq-5$ & & $\cdot 20,2: \leq 20$ \\
$9-6$ & 31 & $-1,0(2,8)$ & $\cdot 1,8: \geq 2$ & $26,0(5,5)$ & $\cdot 31,5: \geq 32$ \\
& & & $\cdot-3,8: \leq-4$ & & $\cdot 20,5: \leq 20$ \\
\hline
\end{tabular}

Nota: Intervalo que incluye puntuaciones por debajo y por encima de una desviación típica; Lista C: mediación morfosintáctica con alta carga gramatical; Lista L: mediación semántica con alta carga de significado; MSA: memoria secuencial auditiva; MV: memoria verbal $(\mathrm{L}+\mathrm{C})$

\section{Discusión y Conclusiones}

El propósito general de este estudio fue analizar la relación entre memoria secuencial auditiva y memoria verbal, así como entre estas variables y la edad mental del alumnado con discapacidad intelectual. Se pretendía que las relaciones encontradas sustentaran la construcción de dos baremos representativos de los participantes en el estudio, en los que se mostrasen las puntuaciones equivalentes de cada grupo conformado según la edad mental del sujeto, y las puntuaciones en memoria secuencial auditiva, en las listas de oraciones del SentRep (Lsemántica y C-morfosintáctica) y en memoria verbal.

En primer lugar, se realizó un análisis factorial exploratorio para evaluar la escala construida en este estudio y que revela la existencia de un solo factor que explica el $86.11 \%$ de la varianza total y cuyas cargas factoriales son superiores a .90. Además, se comprueba una elevada consistencia interna que sirve como indicador de la homogeneidad global y la adecuada interdependencia de las pruebas utilizadas en la evaluación. 
Por otro lado, el análisis correlacional confirma relaciones significativas y directas entre todas las variables consideradas, que permiten afirmar que a mayor edad mental le corresponden mayores puntuaciones en memoria secuencial auditiva, en las dos listas de oraciones del SentRep y en memoria verbal, lo que justifica que cada una de las listas se relacione con capacidades específicas susceptibles de ser evaluadas y comparadas (el porcentaje de la variación en cada lista explicado por la otra es del 67\%), y que pueda usarse la edad mental, calculada a partir de la prueba de memoria secuencial auditiva considerada como prueba criterio en este trabajo, para la elaboración de baremos. Todo esto en consonancia con estudios previos que señalan que la prueba de memoria secuencial auditiva del ITPA refleja la capacidad primaria de memoria secuencial fonológica a corto plazo del almacén fonológico (Baddeley, 2012; Cowan, 2008; Hidalgo, 2014); la lista C incluye oraciones encuadrables en lo que Baddeley et al. (2009) denominan oraciones restrictivas, por lo que tendría que ver con los mecanismos automáticos de codificación morfosintáctica a corto plazo de oraciones; y asimismo, la lista L del SentRep, incluye oraciones encuadrables en lo que Baddeley et al. (2009) denominan oraciones naturales abiertas, por lo que tendría que ver con los mecanismos automáticos de codificación semántica a corto plazo de oraciones. Por lo que los resultados de este estudio justifican que sea preciso resolver los problemas relacionados con el uso del SentRep en población con discapacidad intelectual, y avalan al tiempo la necesidad de disponer de baremos específicos para personas con este trastorno del neurodesarrollo en población española.

Una vez analizadas las relaciones y confirmada su significatividad se configuran varios grupos según la edad mental obtenida a partir de las puntuaciones en la prueba criterio de memoria secuencial auditiva, estableciendo las equivalencias de cada uno con dicha puntuación, la de las dos listas de oraciones del SentRep y la de memoria verbal, pudiendo conocer a partir de las mismas el nivel de desarrollo de la memoria inmediata asociada a las capacidades automáticas verbales en general, y las semánticas y morfosintácticas en particular. Se observa que los resultados obtenidos en estos baremos muestran la tendencia de que, en los grupos de edad mental, la cantidad de material recordado sea menor en mediación morfosintáctica (lista C) que en mediación semántica (lista L). Resultados en la línea del modelo de Baddeley et al. (2009), que afirman que el tipo de unidades formadas en la memoria episódica, puede ser un factor importante en cuanto a su extensión y durabilidad en la memoria a corto plazo y su paso a la memoria a largo plazo. El funcionamiento en la memoria a corto plazo de las oraciones restrictivas, se asemeja más al de las listas de palabras no relacionadas que el de las oraciones 
naturales abiertas, y estas oraciones se benefician especialmente de la codificación morfosintáctica automática, que, si bien fortalece la agrupación secuencial de palabras, no produce gran mantenimiento en el tiempo. Sin embargo, la formación de grupos en el caso de las oraciones naturales abiertas, opera bajo mecanismos automáticos de codificación semántica, que facilitan el paso de la información a la memoria episódica a largo plazo (pues los fragmentos semánticos poseen mayor sentido y relevancia para el individuo, y por ello se agrupan en unidades mayores y se mantienen durante más tiempo). Las listas de palabras no relacionadas, sin embargo, se ven poco afectadas por la codificación sintáctica, la codificación semántica y la memoria a largo plazo episódica. Por ello, se sobrescriben más fácilmente, pues la amplitud primaria de la memoria a corto plazo es muy limitada, y es necesario que el almacén se vacíe para que la nueva información entrante se procese (y algo similar ocurre con las oraciones de la lista $\mathrm{C}$ respecto al procesamiento morfo-sintáctico).

Por otro lado, aunque Sedó (2004) afirma que es evidente que en los sujetos con discapacidad intelectual se produce una reducción importante tanto de los recursos semánticos como de los sintácticos, y a pesar de que a la vista de los resultados generales se podría pensar, por su progresión, que esta reducción es siempre similar respecto a ambas aptitudes, el estudio de casos individuales muestra que existe una gran heterogeneidad, y es ahí donde el uso del procedimiento presentado en este trabajo cobra sentido.

Se han calculado también puntuaciones ipsativas que según la edad mental del sujeto son indicativas de la existencia de diferencias significativas o no entre el recuerdo de las oraciones presentadas y la memoria secuencial auditiva y verbal. A partir de las mismas cabe la posibilidad de analizar la homogeneidad del desarrollo del recuerdo inmediato de componentes verbales del lenguaje. La principal utilidad del procedimiento de evaluación y comparación propuesto se relaciona, pues, con la práctica clínica. Radica, en primer lugar, en la posibilidad de evaluar y establecer un diagnóstico diferencial respecto a las dificultades de memoria y lenguaje observadas en alumnado con discapacidad intelectual, que ayudará a tomar decisiones respecto a la educación especial y la rehabilitación. Una perspectiva nueva en cuanto a que va destinada a alumnado con discapacidad intelectual, pero ya había sido iniciada por Gathercole y Alloway (2008), quienes aportan un instrumento de medida de la memoria de trabajo que, plicado a niños y niñas en edad escolar, es capaz de identificar niños en riesgo y proporcionar métodos para ayudarles (Baddeley, 2012). 
Queda justificada por lo tanto la complementariedad de las pruebas aplicadas en este estudio. Desde el punto de vista neuro-anatómico-funcional la prueba de memoria secuencial auditiva indicaría el estado de las estructuras y vías dorsales del hemisferio izquierdo relacionadas con el procesamiento de los sonidos del habla y su integración sensorio-motora; la lista C el estado de las estructuras y vías dorsales izquierdas de procesamiento sintáctico, el cual es necesario para establecer las relaciones entre los componentes de las oraciones complejas (en especial el estado del área posterior del córtex temporal superior, el Broca opercular y su conexión mediante la sección larga del fascículo arqueado); y la lista L el estado de las estructuras y vías dorsales que procesan los papeles o roles temáticas de los constituyentes de las oraciones (en especial el estado del área posterior del córtex temporal superior, el giro angular y su conexión mediante la sección posterior del fascículo arqueado). Estos tres procesos automáticos son complementarios y necesarios para establecer el significado literal de las oraciones, información imprescindible para acceder al sentido de los mensajes lingüísticos en los niveles superiores de la memoria episódica y la comprensión verbal (Catani y Bambini, 2014; Hickok y Poeppel, 2015). Asimismo, en la actividad aplicada hay que tener en cuenta también que en el alumnado con discapacidad intelectual la memoria de trabajo guarda una estrecha relación con el aprendizaje y las funciones mentales superiores (Hartman, Houwen, Scherder y Visscher, 2010; Schuchardt, Gebhardt y Mäehler, 2010), al igual que sucede en alumnos de desarrollo típico (González, Fernández y Duarte, 2016).

Son varias las limitaciones de este estudio que deberían ser abordadas en investigaciones posteriores. En primer lugar, son escasos los instrumentos de valoración para el alumnado con discapacidad intelectual, y en concreto en el uso del SentRep, el problema radica en la falta de normas obtenidas con población española, junto a las dificultades de normalización que supone trabajar con alumnos con discapacidad intelectual. En segundo lugar, una limitación importante tiene que ver con la muestra, por un lado, por la selección no probabilística de la población de estudio, y por otro, por su tamaño y heterogeneidad que podría distorsionar los datos en algunos de ellos. Obtener baremos del rendimiento en una prueba con una muestra no representativa de la población con discapacidad intelectual no es lo más adecuado, por lo que, con los resultados obtenidos en este estudio, a priori solo es posible comparar la puntuación de un sujeto en relación a su grupo de pertenencia. Por lo tanto, sería aconsejable volver a elaborar los baremos con un número de participantes considerablemente mayor y, ade- 
más, ampliarla a población normal, pues también sería deseable contar con baremos adecuados para esta población.

Investigaciones futuras podrían estudiar la utilidad del procedimiento presentado en el diagnóstico, exploración, investigación, intervención y comprobación de los efectos de programas específicos de entrenamiento, tanto en casos individuales como en las características generales de la discapacidad intelectual. Asimismo, deberían tenerse en cuenta las implicaciones prácticas de este tipo de investigaciones y desarrollar programas de intervención basados en la información que proporcionan estos procedimientos de evaluación. De esta manera se contribuirá a comprobar si en el alumnado con discapacidad intelectual la memoria de trabajo, al igual que apuntan los datos recogidas en muestras de desarrollo típico, es mejor predictora del aprendizaje y rendimiento académico que el CI (Alloway y Alloway, 2010).

\section{Agradecimientos}

Queremos expresar nuestro sincero agradecimiento a la Fundación PROMIVA por permitirnos recoger los datos que necesitábamos, y al Catedrático de Psicología Juan Fernández Sánchez por sus sabios consejos y sugerencias.

\section{Referencias}

Adrover, D., Marron, E. M., Sánchez, I., y Miranda, R. (2014). Neurobiología de los sistemas de aprendizaje y memoria. En D. Redolar, Neurociencia Cognitiva (pp. 405-430). Madrid: Panamericana.

Alloway, T. P., y Alloway, R. G. (2010). Investigating the predictive roles of working memory and IQ in academic attainment. Journal of Experimental Child Psychology, 106(1), 20-29. doi: 10.1016/j.jecp.2009.11.003

APA, American Psychiatric Association (2013). Diagnostic and Statistical Manual of Mental Disorders, Fifth Edition (DSM-5). Arlington, VA (USA): American Psychiatric Publishing.

Arévalo, R., y León, H. (2019). Relación entre memoria secuencial auditiva, integración auditiva y desempeño fonológico en niños de 3 años a 3 años 11 meses con trastorno específico del lenguaje de tipo expresivo. Revista Chilena de Fonoaudiología, 18, 1-14. doi: $10.5354 / 0719-4692.2019 .55320$

Baddeley, A. D. (1986). Working memory. Oxford: Clarendon Press. 
Baddeley, A. D. (2000). The episodic buffer: A new component of working memory? Trends in Cognitive Sciences, 4, 417-423. doi: 10.1016/S1364-6613(00)01538-2

Baddeley A. D. (2007). Working memory, thought and action. Oxford, UK: Oxford University Press.

Baddeley, A. D. (2010). Working memory. Current Biology, 20(4), 136-140. doi: 10.1016/j.cub.2009.12.014

Baddeley, A. D. (2012). Working memory: Theories, models, and controversies. Annual Review of Psychology, 63, 1-29. doi: 10.1146/annurev-psych-120710-100422

Baddeley, A. D., y Hitch, G. J. (1974). Working memory. In G. Bower (Ed.) Recent advances in learning and motivation. New York: Academic Press.

Baddeley, A. D., y Hitch, G. J. (1994). Developments in the concepts of working memory. Neuropsychology, 8, 484-493. doi: 10.1037/0894-4105.8.4.485

Baddeley A. D., Hitch G. J., y Allen R. J. (2009). Working memory and binding in sentence recall. Journal of Memory and Language, 61, 438-56. doi: 10.1016/j.jml.2009.05.004

Baddeley, A. D., y Lieberman, K. (2017). Spatial working memory. En Exploring Working Memory (pp. 206-223). Routledge.

Ballesteros, S., y Cordero, A. (2011). Adaptación española del ITPA, Test Illinois de Aptitudes Psicolingüísticas. Madrid: TEA.

Caplan, D., Waters, G., y DeDe, G. (2008). Specialized verbal working memory for language comprehension. En A. R. Conway, C. Jarrold, M. J. Kane, A. Miyake y J. Towse (Eds.), Variation in working memory (pp. 272-302). New York, NY: Oxford University Press.

Catani, M., y Bambini, V. (2014). A model for social communication and language evolution and development (SCALED). Current Opinion in Neurobiology, 28, 165-171. doi: 10.1016/j.conb.2014.07.018

Cowan, N. (2008). What are the differences between long-term, short-term, and working memory? Progress in Brain Research, 169, 323-338. doi: 10.1016/S0079-6123(07)000209

D’Esposito, M., y Postle, B. R. (2015). The Cognitive Neuroscience of Working Memory. Annual Reviews Psychology, 66, 115-142. doi: 10.1146/annurev-psych-010814-015031

De Noreña, D., Blázquez, J. L., González, B., y Gil, E. (2012). Corteza prefrontal, memoria y funciones ejecutivas. En J. Tirapu-Ustárroz, (Ed.), Neuropsicología de la corteza prefrontal y las funciones ejecutivas (pp. 271-298). Barcelona: Viguera.

Fernández, R., y Gràcia, M. (2013). Lenguaje expresivo y memoria verbal a corto plazo u operativa (working memory) en las personas con síndrome de Down. Revista de Síndrome de Down, 30(4), 122-132. 
Friederici, A. D., y Gierhan, S. M. (2013). The language network. Current Opinion in Neurobiology, 23(2), 250-254. doi: 10.1016/j.conb.2012.10.002

Friederici, A. D., y Singer, W. (2015). Grounding language processing on basic neurophysiological principles. Trends in Cognitive Sciences, 19(6), 329-338. doi: 10.1016/j.tics.2015.03.012

Galvez-Pol, A., Forster, B., y Calvo-Merino, B. (2018). Modulation of motor cortex activity in a visual working memory task of hand images. Neuropsicología, 117, 75-83. doi: 10.1016/j.neuropsychologia.2018.05.005

García-Madruga, J., y Fernández, T. (2008). Memoria operativa, comprensión lectora y razonamiento en la educación secundaria. Anuario de Psicología, 39(1), 133-157.

Gathercole, S. E., y Alloway, T. P. (2008). Working memory and learning: A practical guide. London: Sage.

Goldman-Rakic, P. S. (1998). The prefrontal landscape: implications of functional architecture for understanding human mentation and the central executive. En A. C. Roberts, T. W. Robbins, y L. Weiskrantz (Eds.), The prefrontal cortex: Executive and cognitive functions (pp. 87-102). New York: Oxford University Press.

González, S., Fernández, F. H., y Duarte, J. E. (2016). Memoria de trabajo y aprendizaje: implicaciones para la educación. Saber, Ciencia y Libertad, 11, 161-176.

Guerra, J. V., y De la Peña, C. (2017). Comunicación y memoria visual en escolares con discapacidad intelectual. Una relación clave para la intervención. Indivisa. Boletín de Estudios e Investigación, 17, 179-197.

Hamada, M., y Koda, K. (2011). The role of the phonological loop in English word learning: A comparison of Chinese ESL learners and native speakers. Journal of Psycholinguistic Research, 40(2), 75-92. doi: 10.1007/s10936-010-9156-9

Hartman, E., Houwen, S., Scherder, E., y Visscher, C. (2010). On the relationship between motor performance and executive functioning in children with intellectual disabilities. Journal of Intellectual Disability Research, 54(5), 468-477. doi: 10.1111/j.13652788.2010.01284.x

Hickok, G., y Poeppel, D. (2015). Neural basis of speech perception. Handbook of clinical neurology, 129, 149-160. doi: 10.1016/B978-0-444-62630-1.00008-1

Hidalgo, I. (2014). En busca de variables subyacentes en el trastorno fonológico: la memoria de trabajo. Estudios Interlingüísticos, 2, 27-45.

Jefferies, E., Ralph, M. A., y Baddeley, A. D. (2004). Automatic and controlled processing in sentence recall: The role of long-term and working memory. Journal of memory and language, 51(4), 623-643. doi: 10.1016/j.jml.2004.07.005 
Kirk, S. A., McCarthy, J. J., y Kirk, W. D. (2004). ITPA: Test Illinois de Aptitudes Psicolingüísticas. Madrid: TEA.

Kline, P. (2014). An Easy Guide to Factor Analysis. New York: Routledge.

Logie, R. H. (2011). The functional organization and the capacity limits of working memory. Current Directions in Psychological Science, 20, 240-45. doi: $10.1177 / 0963721411415340$

Manso, A., y Ballesteros, S. (2003). El papel de la agenda visoespacial en la adquisición del vocabulario ortográfico. Psicothema, 15(3), 388-394.

Miolo, G., Chapman, R., y Sindberg, H. (2005). Sentence comprehension in adolescents with Down syndrome and typically developing children. Journal of Speech, Language and Hearing Research, 48(1), 172- 188. doi: 10.1044/1092-4388(2005/013)

Muñoz, M. T., González, C., y Lucero, B. (2009). Influencia del lenguaje no verbal (gestos) en la memoria y el aprendizaje de estudiantes con trastornos del desarrollo y discapacidad intelectual: Una revisión. Revista Signos, 42(69), 29-49. doi: 10.4067/S071809342009000100002

Pelegrina, S., Lechuga, M. T., Castellanos, M. C., y Elosúa, M. R. (2016). Memoria de trabajo. En M. T. Bajo Molina, L. J. Fuentes Melero, J. Lupiañez Castillo, y C. Rueda Cuerva (Coords.). Mente y cerebro: de la psicología experimental a la neurociencia cognitiva (pp. 237-262). Madrid: Alianza Editorial.

Peña-Casanova, J. (2013). Manual de logopedia. Barcelona: Masson.

Potter, M. C., y Lombardi, L. (1990). Regeneration in the short-term recall of sentences. Journal of Memory and Language, 29, 633-654. doi: 10.1016/0749-596X(90)90042-X

Ranganath, C., y Ritchey, M. (2012). Two cortical systems for memory-guided behaviour. Nature Reviews Neuroscience, 13(10), 713. doi: 10.1038/nrn3338

Ritchey, M., Libby, L. A., y Ranganath, C. (2015). Cortico-hippocampal systems involved in memory and cognition: the PMAT framework. En Progress in brain research (Vol. 219, pp. 45-64). Elsevier.

Ruiz-Vargas, J. M. (2010). Manual de psicología de la memoria. Madrid: Editorial Síntesis.

Sedó, M. A. (1990). SentRep: Test of Sentence Repetition. Boston, MA: Boston Public Schools (Mimeo).

Sedó, M. A. (2004). SentRep: dos listas de frases de longitud idéntica para medir los problemas de atención y madurez lingüística. Revista Española de Neurología, 38(10), 924-927.

Schuchardt, K., Gebhardt, M., y Mäehler, C. (2010). Working memory functions in children with different degrees of intellectual disability. Journal of Intellectual Disability Research, 54(4), 346-353. doi: 10.1111/j.1365-2788.2010.01265.x 
Smith, M. M., y Pendleton, L. R. (1990). Space and movement in working memory. Quarterly Journal of Experimental Psychology, 42A, 291-304. doi: 10.1080/14640749008401223

Soprano, A., y Narbona, J. (2007). La memoria del niño. Desarrollo normal y trastornos. Barcelona: Elsevier.

Stephenson, J., y Dowrick, M. (2005). Parents' perspective on the communication skills of their children with severe disabilities. Journal of Intellectual \& Developmental Disability, 30(2), 75-85. doi: 10.1080/13668250500125031

Swanson, H. L., Zheng, X., y Jerman, O. (2009). Working memory, short-term memory, and reading disabilities. A selective meta-analysis of the literature. Journal of Learning Disabilities, 42(3), 260-287.

Tirapu-Ustárroz, J., y Grandi, F. (2016). Memoria: necesidad de una clarificación conceptual. Cuadernos de Neuropsicología/Panamerican Journal of Neuropsychology, 10, 13-31.

Verhagen, J., y Leseman, P. (2016). How do verbal short-term memory and working memory relate to the acquisition of vocabulary and grammar? A comparison between first and second language learners. Journal of Experimental Child Psychology, 141, 65-82.doi: 10.1016/j.jecp.2015.06.015

Weill, F. (2011). The role of verbal working memory in new word learning in toddlers 24 to 30 months. Seton Hall University Dissertations and Theses (ETDs).

Wechsler, D. (2005). WISC-IV. Escala de inteligencia de Wechsler para niños-IV. Madrid: TEA Ediciones.

Recibido: 14-01-2020

Aceptado: 22-04-2020 